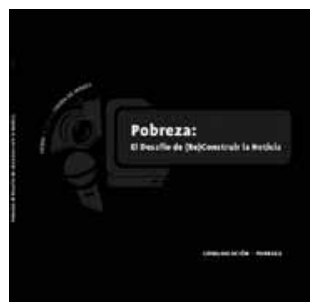

Universidad de Viña del Mar y Alianza Comunicación y Pobreza

Pobreza: El desafío de (Re)Construir la noticia.

Un estudio de la prensa escrita de VALParaíso.

Santiago de Chile, 2007

85 páginas

\title{
Claudia Farfán
}

Los medios de comunicación desempeñan un papel crucial en la formación de la opinión pública y en la introducción de nuevas temáticas en el debate nacional. En esa línea, y considerando que una de las directrices del gobierno de la Presidenta Michelle Bachelet es la construcción de un Sistema de Protección Social, el enfoque y tono del debate sobre el tema de la pobreza ocupa un sitial fundamental respecto a los avances sociales concretos y también a nivel de discurso, que se puedan alcanzar en este ámbito.

Este último punto ha sido una preocupación del programa Comunicación y Pobreza, el cual ha desarrollado una serie de investigaciones, seminarios y publicaciones, desde el año 2004, que han abordado el tratamiento del tema de la pobreza en los medios de comunicación, tanto a nivel nacional como regional. Su última investigación titulada "Pobreza: el desafío de (re)construir la noticia. Un estudio de la prensa escrita en la Región de Valparaíso” (2007) realiza un análisis de los tres principales diarios de la V Región-El Mercurio de Valparaíso, La Estrella de Valparaíso y El Observador de Viña del Marcon el objeto de indagar en las características informativas de la prensa escrita al momento de abordar la vulnerabilidad social.

Cabe destacar que los resultados de este estudio permiten, por primera vez, acceder a un diagnóstico sobre cómo la prensa escrita de la Región de Valparaíso mira, aborda e informa los hechos vinculados a la pobreza, exclusión y la desigualdad. Entre las conclusiones, la investigación reveló puntos de encuentro con publicaciones anteriores realizadas por el programa, dando cuenta de la vigencia de ciertas prácticas periodísticas que se mantienen arraigadas en la cobertura de la pobreza.

Entre los aspectos criticables, el estudio expone la falta de proactividad de la línea editorial de los medios de prensa para indagar en el tema y sus alcances por iniciativa propia. La mayoría de las noticias con 
contenido de pobreza responden a hitos o hechos puntuales, y en muy pocos casos responden al interés informativo por hacer seguimiento a las diversas aristas de un hecho. Otro punto en cuestión es la ausencia de las voces de los parlamentarios, ya que en sólo el 3\% del total de las noticias se detectaron opiniones o valoraciones sobre la pobreza de este actor nacional. La gran presencia pública que tiene el Congreso en la región, hacía presagiar que el resultado sería distinto y que los legisladores tendrían un discurso con presencia permanente en los diarios. Por otra parte, en los tres periódicos analizados destaca positivamente la omisión de construcciones arquetípicas en torno a la pobreza y la presencia de causas y soluciones en la mayoría de las noticias.

Finalmente, cabeseñalar que el estudiobuscólevantarun diagnóstico que contribuya a abrir el debate regional sobre el tratamiento de la pobreza en los medios de comunicación y las posibilidades que existen para mejorarlo o profundizar aquellas prácticas positivas. 